\title{
Clinical Wellness Coaching: A Brief Assessment of the Development, Implementation, and 3-year Experiences of Interns in a Graduate Certification Program
}

\author{
Marion W. Evans Jr. \\ University of Southern Mississippi, will.evans@usm.edu \\ Melissa Cox \\ Mississippi State University, mcox@foodscience.msstate.edu \\ Melika Forooshani \\ Mississippi State University, mk1658@msstate.edu
}

Follow this and additional works at: https://nsuworks.nova.edu/ijahsp

Part of the Medicine and Health Sciences Commons

\begin{abstract}
Recommended Citation
Evans MW, Cox M, Forooshani M. Clinical Wellness Coaching: A Brief Assessment of the Development, Implementation, and 3-year Experiences of Interns in a Graduate Certification Program. The Internet Journal of Allied Health Sciences and Practice. 2021 Oct 01;19(4), Article 1.
\end{abstract}

This Concept Piece is brought to you for free and open access by the College of Health Care Sciences at NSUWorks. It has been accepted for inclusion in Internet Journal of Allied Health Sciences and Practice by an authorized editor of NSUWorks. For more information, please contact nsuworks@nova.edu. 


\title{
Clinical Wellness Coaching: A Brief Assessment of the Development, Implementation, and 3-year Experiences of Interns in a Graduate Certification Program
}

\begin{abstract}
Purpose: Mississippi is one of sickest states according to national assessments and ranks $49^{\text {th }}$ for overall health outcomes. In addition, Mississippi is the most overweight and obese state, the least physically active state, and ranks second in adult hypertension. This paper reviews the development and threeyear assessment of a novel wellness coaching program developed at one southeastern university in a partnership with a foundation whose primary interest was to see more wellness and lifestyle coaching offered in primary medical clinics in the state. Methodology: A model for training graduate students in wellness coaching was envisioned and interdisciplinary training model developed. The design and implementation of the program is described, as well as the programmatic evaluation of the first 3 cohorts of interns including the types of conditions coached and the overall intern experience. Results: Interns were placed in 9 different Mississippi counties over the first three years. In total, 1,186 patients were coached in the field over the three years by 15 interns. Of those, $74 \%$ were new patients and $26 \%$ were follow-up patients at the clinics. The top three reasons for wellness coaching were weight management $(n=252$, $21.3 \%)$ followed by diabetes $(n=238,20.1 \%)$, and metabolic issues $(n=204,17.2 \%)$. Interns were surprised at the level of comorbidities and low health literacy, and overall ratings from medical practitioners and staff were very favorable. Conclusion: Graduate level wellness coaching training can develop coaches to aid clinical healthcare providers in reaching patients in need of setting personal lifestyle-related goals for improving overall health outcomes. Interns must be prepared in states like Mississippi for complications such as low health literacy and low literacy situations as well as the comorbidities that a typical patient will have. Barriers to successful interaction with the wellness coach can be mitigated by having staff fully understand their role.
\end{abstract}

\section{Author Bio(s)}

Marion W. Evans, Jr. PhD, MCHES is an Executive Associate Dean and Professor of Public Health at The University of Southern Mississippi, College of Nursing and Health Professions in Hattiesburg, MS

Melissa Cox, PhD, CHES is an adjunct professor at Mississippi State University in the Department of Food Science, Nutrition and Health Promotion in Starkville, MS

Melkia Forooshani, MD is a graduate student in health promotion at Mississippi State University in the Department of Food Science, Nutrition, and Health Promotion in Starkville, MS

\section{Acknowledgements}

The authors are grateful for the funding provided by the Blue Cross and Blue Shield of Mississippi Foundation (BCBSMSF-2018-131B) and full support of the wellness coaching program, from conception to implementation. In addition, they wish to thank the Mississippi Agricultural and Forestry Experiment Station for research support. 


\title{
IIIAHSP ${ }^{\mathrm{m}}$ \\ The Internet Joumnal of Allied Health Sciences and Practice Vol. 19 No. 4 ISSN 1540-580X
}

\section{Clinical Wellness Coaching: A Brief Assessment of the Development, Implementation, and 3-year Experiences of Interns in a Graduate Certification Program}

\author{
Marion W. Evans, Jr. \\ Melissa Cox \\ Melika Forooshani \\ Mississippi State University \\ United States
}

\begin{abstract}
Purpose: Mississippi is one of sickest states according to national assessments and ranks $49^{\text {th }}$ for overall health outcomes. In addition, Mississippi is the most overweight and obese state, the least physically active state, and ranks second in adult hypertension. This paper reviews the development and three-year assessment of a novel wellness coaching program developed at one southeastern university in a partnership with a foundation whose primary interest was to see more wellness and lifestyle coaching offered in primary medical clinics in the state. Methodology: A model for training graduate students in wellness coaching was envisioned and interdisciplinary training model developed. The design and implementation of the program is described, as well as the programmatic evaluation of the first 3 cohorts of interns including the types of conditions coached and the overall intern experience. Results: Interns were placed in 9 different Mississippi counties over the first three years. In total, 1,186 patients were coached in the field over the three years by 15 interns. Of those, $74 \%$ were new patients and $26 \%$ were follow-up patients at the clinics. The top three reasons for wellness coaching were weight management $(n=252$, $21.3 \%)$ followed by diabetes $(n=238,20.1 \%)$, and metabolic issues $(n=204,17.2 \%)$. Interns were surprised at the level of comorbidities and low health literacy, and overall ratings from medical practitioners and staff were very favorable. Conclusion: Graduate level wellness coaching training can develop coaches to aid clinical healthcare providers in reaching patients in need of setting personal lifestyle-related goals for improving overall health outcomes. Interns must be prepared in states like Mississippi for complications such as low health literacy and low literacy situations as well as the comorbidities that a typical patient will have. Barriers to successful interaction with the wellness coach can be mitigated by having staff fully understand their role.
\end{abstract}

Keywords: wellness, wellness coaching, lifestyle medicine, prevention 


\section{INTRODUCTION}

The term wellness is said to date back to mid-1600s and forms of holistic care can be traced back to Taoism and Buddhism. ${ }^{1}$ Today, wellness coaching, which is a form of lifestyle coaching or lifestyle medicine is a part of a larger holistic effort to help patients improve health and avoid unnecessary health risks by some form of prevention or treatment that might also reduce or reverse chronic conditions. ${ }^{2}$ Wellness coaching has been described as

"A patient-centered approach wherein patients at least partially determine their goals, use self-discovery, or active learning processes together with content education to work toward their goals and self-monitor behaviors to increase accountability, all within the context of an interpersonal relationship with a coach."

America's Health Rankings looks at each state through various metrics and lists the states in order of the healthiest to the least healthy. ${ }^{4}$ In 2020, the report listed the state of Mississippi at $47^{\text {th }}$ with its availability of clinical care, health behavior scores, and $49^{\text {th }}$ for overall health outcomes. ${ }^{5}$ The only the state that fared worse in overall health outcomes was the state of Louisiana. In addition, Mississippi is the most overweight and obese state, the least physically active state, and ranks second in prevalence of adult hypertension. ${ }^{6}$

This paper reviews the development and three-year assessment of a novel wellness coaching program developed at Mississippi State University in a partnership with a foundation whose primary interest was to see more wellness and lifestyle coaching offered in primary medical clinics in the state. A model for training wellness coaches was developed working with the foundation, a university health center, and faculty within the department housing the nutrition, dietetics, and health promotion programs. The model and the experiences of graduate students in the coaching program are also described.

\section{Wellness Coaching in a Clinical Setting}

DeJesus and colleagues assessed the impact of a 12-week wellness coaching program on self-care among primary care patients with pre-diabetes. ${ }^{7}$ They found a significant increase in physical activity levels, healthy eating, self-efficacy, and quality of life scores among participants within 6-weeks of the program's start. They suggested health education alone may not be enough to motivate some patients to make necessary lifestyle modifications. A systematic review of the literature on health and wellness coaching described in 2013 reviewed 800 abstracts and 284 PubMed papers and outlined a definition of wellness coaching stating it was an approach to bring about change in health behaviors with patient-determined goals, active learning, encouraged accountability, and patient education with the ultimate goal of reducing the global burden of chronic disease. ${ }^{3}$ The key is having a trained professional to assist patients in goal-setting and use appropriate techniques that move them forward to lasting behavior change. Rutten and colleagues described a study on promotion of healthy diet and physical activity within a primary care setting using wellness coaching and found more autonomous motivation existed among patients within 4 months of receiving coaching. ${ }^{8}$ They found the use of Motivational Interviewing (MI) skills with coaches to be important as well as an external locus of control within the patient. ${ }^{9}$

In a study on nutritional habits without a diet prescription, wellness coaching via face-to-face coaching or virtual coaching improved daily physical activity levels and energy expenditure in patients. ${ }^{10}$ Total body fat and body weight was reduced in patients after 12 sessions. Other studies indicate face-to-face or phone-based and virtual coaching can be effective in clinical setting as well. ${ }^{11,12}$ Even e-mail messaging or follow-up letters can support positive changes in patients working towards lifestyle change. Boccio reported on a tobacco cessation coaching program utilizing telephone-based and face-to-face coaching in patients within a Kaiser Permanente program and found after adjusting for confounding, quit rates were higher in the coaching participants than matched controls. ${ }^{13}$ Further, that telephonic coaching was just as effective as in-person cessation classes and had higher quit rates than no coaching.

In most of the studies on wellness or lifestyle coaching, it has been stressed that this is not a provider-driven intervention with patients but rather a patient-driven, patient-motivated partnership with the coach that must start out and remain patientcentered. ${ }^{14,15}$ Wellness coaching has supportive literature to indicate it can assist in managing chronic conditions such as heart disease, hypertension, obesity, improve healthy weight and physical activity levels as well as to promote overall wellness in general. ${ }^{15}$ Coaching programs can be successfully integrated into primary care settings as well as exercise or medical fitness center programs. ${ }^{16}$

\section{METHODOLOGY}

\section{Wellness Coaching Model Design}

Due to the educational nature of the study and evaluation process, the project received an exempt status with the institutional review board at the university. The director of the university health and wellness program, the department head for Food, Science, Nutrition, and Health Promotion initially met with foundation representatives in the fall of 2015 . There, they discussed the need for a wellness coaching training program in Mississippi. An initiative developed by Blue Cross and Blue Shield of Mississippi had previously placed dietitians in the clinical setting with some wellness coach training, and improvements had 
been noted in one rural health clinic in the state. From there, a model for training graduate students in wellness coaching was envisioned and interdisciplinary training model developed by the director of the health and wellness program and the department head. The general idea was to have students from a nutrition or health promotion background train at the graduate level such that they would have basic health education skills and know their way around a primary care clinic. Ideas were vetted with health promotion and nutrition faculty as well as the health education specialists, the medical staff in the campus health center, and fitness center directors. Input was also solicited from coaches within the Blue Cross and Blue Shield program as well. Specific training in Ml was also seen as critical to the training and coaching process.

Individual wellness coaching in a clinical setting is not typically taught in a health promotion curriculum. It was decided by the team reviewing the concepts for wellness coach training that 4 pre-requisite courses would be needed that existed within the current health promotion curriculum at the master's level. Those were an introductory course, a chronic disease management course, a health behavior course, and an epidemiology course. Those would serve as a basis for the added courses to be developed providing skills directly related to wellness coaching. Two training courses were developed as internship courses. One was a 3-credit hour didactic course that included 150 hours of shadowing in the campus health center, campus recovery center, and mental health counseling but focused most on primary care providers, the dietitian, and the health promotion staff. The second was a field-based internship at 6-credit hours, requiring 300 contact hours in a primary medical care setting somewhere in Mississippi. It was agreed that clinics that had become early adopters of a Blue Cross and Blue Shield of Mississippi program involving wellness coaching would be targeted for those internships. Syllabi were developed and approved by the various curriculum committees, and a 21-hour Clinical Health Promotion and Wellness Coaching Graduate Certificate was approved within the health promotion master's program. Course programming was adjusted as the program developed but included training in Ml, clinical protocols such as bloodborne pathogen training, HIPPA training, and standardized patient encounters were developed to assess interns as they moved into actual field-based coaching. The specific learning objectives for the practicum part of the program were clarified:

1. Describe a common health issue that can be addressed through wellness coaching.

2. Assess the patient's "stage" of readiness for change based on verbal cues and interaction.

3. Design a basic wellness plan based on prescribed needs from a licensed health care provider.

4. Complete a wellness coaching session with a patient or standardized patient using acceptable techniques common to clinical health promotion.

5. Develop a follow-up plan for the patient including goals mutually agreed upon in an initial coaching setting.

6. Summarize existing health conditions and initial wellness coaching progress of a typical patient in a case-study format.

The specific learning objectives for the field-based internship were as follows:

1. Students will be able to apply culturally competent, goal-based health promotion and wellness coaching techniques in a clinical or community setting.

2. Students will be able to develop and demonstrate a case-specific wellness coaching program applying best practices from the field of clinical health promotion.

Table 1 lists the basic training model and assessments in both the practicum part of the program (150-hour shadowing and didactic education) and the field-based internship (300-hour program in primary care clinics).

Table 1 Training model for practicum and internship

\begin{tabular}{|c|c|c|c|c|c|}
\hline Training Level & Content & $\begin{array}{l}\text { Practicum- } \\
\text { based }\end{array}$ & Internship & Key Trainer(s) & Assessment \\
\hline Didactic & $\begin{array}{l}\text { Weekly lectures } \\
\text { on clinical } \\
\text { engagement and } \\
\text { patient coaching } \\
\text { techniques }\end{array}$ & Yes & No & $\begin{array}{l}\text { PhD, CHES, } \\
\text { MCHES }\end{array}$ & $\begin{array}{l}\text { Written } \\
\text { evaluation, } \\
\text { standardized } \\
\text { patient } \\
\text { examination, } \\
\text { case-study } \\
\text { reports on } \\
\text { chronic medical } \\
\text { topics }\end{array}$ \\
\hline Shadowing & $\begin{array}{l}\text { All primary care } \\
\text { and campus- } \\
\text { based clinic } \\
\text { personnel } \\
\text { including } \mathrm{MD} \text {, }\end{array}$ & $\begin{array}{l}\text { Yes, } 150 \text { contact } \\
\text { hours ( } 3 \\
\text { graduate } \\
\text { semester credit } \\
\text { hours) in clinical }\end{array}$ & No & $\begin{array}{l}\text { MD, DO, PhD, } \\
\text { CHES, MCHES, } \\
\text { NP, RD, RP, DC }\end{array}$ & $\begin{array}{l}\text { Written } \\
\text { evaluation, } \\
\text { standardized } \\
\text { patient } \\
\text { examination, }\end{array}$ \\
\hline
\end{tabular}




\begin{tabular}{|c|c|c|c|c|c|}
\hline & $\begin{array}{l}\mathrm{DO}, \mathrm{DC}, \mathrm{NPs}, \\
\text { pharmacists, } \\
\text { dietician, health } \\
\text { education } \\
\text { specialists }\end{array}$ & $\begin{array}{l}\text { setting with on } \\
\text { campus } \\
\text { programs and } \\
\text { health center }\end{array}$ & & & $\begin{array}{l}\text { case-reports on } \\
\text { cases seen in } \\
\text { clinical } \\
\text { shadowing, } \\
\text { feedback from } \\
\text { practitioners }\end{array}$ \\
\hline Rotations & $\begin{array}{l}\text { Rotations with } \\
\text { MD, DO, NP, } \\
\text { nurses, RD, } \\
\text { pharmacists, } \\
\text { Campus } \\
\text { Recovery Center, } \\
\text { Personal Trainer }\end{array}$ & $\begin{array}{l}\text { Yes, } 150 \text { contact } \\
\text { hours ( } 3 \\
\text { graduate } \\
\text { semester credit } \\
\text { hours) in clinical } \\
\text { setting with on } \\
\text { campus } \\
\text { programs and } \\
\text { health center }\end{array}$ & No & $\begin{array}{l}\text { MD, PhD, CHES, } \\
\text { MCHES, NP, RD, } \\
\text { RP, DC, personal } \\
\text { trainer }\end{array}$ & $\begin{array}{l}\text { Written } \\
\text { evaluation, } \\
\text { standardized } \\
\text { patient } \\
\text { examination, } \\
\text { case-reports on } \\
\text { cases seen in } \\
\text { clinical } \\
\text { shadowing, } \\
\text { feedback from } \\
\text { medical director } \\
\text { and other } \\
\text { practitioners } \\
\text { (campus health } \\
\text { clinic) }\end{array}$ \\
\hline Field-based & $\begin{array}{l}\text { Direct, face-to- } \\
\text { face and } \\
\text { telephonic } \\
\text { coaching in a } \\
\text { primary care } \\
\text { medical setting } \\
\text { under direction of } \\
\text { nurse practitioner } \\
\text { and/or physicians }\end{array}$ & No & $\begin{array}{l}\text { Yes, } 300 \text { contact } \\
\text { hours, } 6 \\
\text { graduate } \\
\text { semester credit } \\
\text { hours) }\end{array}$ & $\mathrm{MD}, \mathrm{DO}, \mathrm{DC}, \mathrm{NP}$ & $\begin{array}{l}\text { Written case } \\
\text { report, written } \\
\text { reflections } \\
\text { (weekly), final } \\
\text { capstone report } \\
\text { on overall } \\
\text { experience } \\
\text { presented to } \\
\text { peers and } \\
\text { faculty, direct } \\
\text { assessment of } \\
\text { clinic director, } \\
\text { report of patients } \\
\text { coached, } \\
\text { conditions } \\
\text { coached for, and } \\
\text { outcomes over } \\
10 \text { weeks }\end{array}$ \\
\hline
\end{tabular}

\section{Incentives for Interns and Grant Support}

A grant from the Blue Cross and Blue Shield of Mississippi Foundation allowed us to support interns in the summer internship by the second year so they were paid a stipend for living expenses along with most of the other support expenses they needed such as uniforms, models for educating patients, books, fees, and travel. Their wellness coaches also assisted with the introduction in most cases, to clinical staff because Blue Cross and Blue Shield coaches had rotated through those clinics where early adopter practitioners were practicing. This was very helpful and having the professional coach on hand for the first day was also very beneficial to interns as they transitioned into the clinical internship in the medical clinic.

\section{Program Outcome Evaluation}

Program outcome evaluation of the education program would center on the intern's experience, types of patients seen, and success in goal setting with patients. This also included an evaluation of the intern from the health center on campus, and an evaluation from the medical clinic in the field as well as the didactic training course grades and assessment with a standardized patient encounter as a final exam for the practicum. Quantitative and qualitative assessments of the field-based experience in primary medical care settings over a three-year period were also made and are reported as a part of this manuscript. Interns were required to keep a spreadsheet as a part of the field-based internship and report on patients coached, goals set, and 
goals attempted by patients. In addition, a capstone assignment required them to do a qualitative, reflective review of the experience. Those were reviewed for thematic trends using a generic qualitative assessment. ${ }^{17}$ Basic demographics are reported where possible, along with characteristics of patients coached, and the nuances of the coaching experience with interns. Interns reported reasons for the clinical encounter, how they assisted patients with setting goals, and follow-up to the degree of adherence to goals set. They reflected weekly on their experience and that culminated into their capstone project. All medical clinic directors rated interns at the end of the experience on a categorical scale: "outstanding, more than satisfactory, satisfactory, needs improvement, or unsatisfactory."

It should be noted that interns in the field-based internship in the summer of 2020 were given the option to virtual coaching due to a coronavirus pandemic and some were able to continue with face-to-face coaching.

\section{RESULTS}

Interns were placed in 9 different Mississippi counties over the course of the program's first three years. Some of these were urban and some were rural. A table indicating those counties along with a map is provided as Table 2, and Figure 1 (Appendix).

Table 2. County, population, and intern placement

\begin{tabular}{|l|l|l|l|}
\hline County & City & Population & Setting \\
\hline Oktibbeha & Starkville & 49,587 & Urban \\
\hline Pearl River & Picayune & 55,535 & Rural \\
\hline Lee & Tupelo & 85,436 & Urban \\
\hline Monroe & Aberdeen & 35,252 & Rural \\
\hline Sunflower & Indianola & 25,110 & Rural \\
\hline Madison & Madison & 106,272 & Urban \\
\hline Rankin & Brandon & 155,271 & Urban \\
\hline Hinds & Clinton & 231,840 & Rural \\
\hline Harrison & Biloxi & 208,080 & Urban \\
\hline
\end{tabular}

Mississippi population at midyear $=2,976,149^{18}$

In total, 1,186 patients were coached in the field over the three-year period from $2018-2020$ by 15 interns. Of those, $74 \%$ were new patients and $26 \%$ were follow-up patients at the clinics. The top three reasons for wellness coaching were weight management $(n=252,21.3 \%)$ followed by diabetes $(n=238,20.1 \%)$, and metabolic issues $(n=204,17.2 \%)$. Table 3 lists most common conditions coached along with numbers of patients and percent. In addition, no intern rated below satisfactory in the clinic director evaluation and all but two rated, "more than satisfactory or outstanding." Many of the clinics were involved with the internship for the three-year evaluation period.

Table 3. Common conditions coached

\begin{tabular}{|l|l|l|}
\hline Condition & Number & Percent \\
\hline Tobacco cessation & 75 & 6.3 \\
\hline Diabetes & 238 & 20.1 \\
\hline Weight management & 252 & 21.3 \\
\hline Cholesterol & 119 & 10.0 \\
\hline Hypertension & 195 & 16.4 \\
\hline Combo/metabolic & 204 & 17.2 \\
\hline General wellness & 49 & 4.1 \\
\hline Other & 54 & 4.6 \\
\hline Total & 1186 & 100 \\
\hline
\end{tabular}

\section{Qualitative Themes Emerging from Intern Capstone Review of Experience}

Two thematic areas seen each year in intern reflections was the number of comorbid conditions interns saw in the clinical setting in the field-based internship and health literacy issues. The following summed up those reflections.

"There were a lot of comorbidities. At least half had more than one health condition they were being seen for."

"Health literacy was low. Much lower than I expected."

Other areas interns discussed were related to having to have an adjustment period in the clinical setting. At times, some staff would not understand why they were there, and treated them more like observers until they had a better idea of what coaching 
was about. In some group practices, some doctors would refer patients to them for coaching and some would not. The following were some experiential outcomes interns reflected on in their final capstone project describing the experience:

"Having an adjustment period so that staff and providers within the clinics were more comfortable referring patients to the coaches was needed."

"Motivational Interviewing took some time to get used to. With time and use, it become more natural to speak with open-ended questions, and use the methods learned with greater levels of expertise."

"People who are more disadvantaged and struggling are not focused on their health."

"A priority concern may have originally been diet or exercise, but sleep, stress, alcohol, or financial struggles were oftentimes a much bigger concern for patients."

"Listening skills and empathy were all further developed, and MI skills improved in the internship."

"l liked being part of the team in the clinics."

"There are a lot of opportunities and needs in Mississippi for health coaches!"

\section{DISCUSSION}

Mississippi's health outcomes are among the worst in the United States..$^{4-6}$ In addition, overall literacy levels are very poor. ${ }^{19}$ That makes it likely that health literacy is also very low. This complicates the doctor and patient interaction. Wellness coaches can bridge that gap. A specific training program can help make that possible by placing a non-physician educator and coach in the clinical setting. This has been shown to be effective when medical assistants provided coaching in a healthcare setting and when medical interns provided it.20,21 In our program, most of the physicians and nurse practitioners they interacted with learned over the 10-week period what interns were doing and that they had skill levels that were helping patients. However, the setting varied. Unofficially, some interns said they were brought into the room with the patient and handed off by the doctor allowing coaching to occur in the treatment room at the encouragement of the clinician. Others said they were stuck at the end of the hall and the patient had to walk down to see them. They perceived this as a barrier as occasionally, the patient would simply walk out and not come to their room for coaching or would complain to them that they either didn't have the time or did not want to be coached. The intern would give them a card and ask them to call them if they changed their mind. Venditti and colleagues described some barriers to lifestyle coaching when applied to weight loss and physical activity adherence. ${ }^{22}$ Those included social cues, thought or mood, time management, illness, or general motivation among others. Clearly, if a clinical provider does not cue the patient to listen to the coach, that is a barrier and the comments are well-taken from interns who found that when a person has other issues surrounding poverty or social dynamics of stress on top of a health condition, they can be less focused on their health even though it can all be interrelated.

At times, this program was difficult to assess as it was an educational program and not a research experiment. We did not have full details on patients nor access to direct patient outcomes, as that was not the intention of the assessment. Further, the SARS CoV2 pandemic caused us to send interns home in the middle of their term in 2020 when the practicum part of the training was just getting underway. Fortunately, we had all of the didactic content in an online course shell, so it was easily accessed when a transition to off-campus learning was mandated. In that spring term, Blue Cross and Blue Shield of Mississippi wellness coaches assisted us by doing one-on-one video or phone-based mentoring with our interns and that was well-received. Even though some interns coached patients virtually in 2020, they all reported very similar experiences and patient outcomes.

\section{Clinical Training in a Campus Health Center}

Our university did not have a medical or nursing school but had a bustling health center on campus with several physicians and nurse practitioners. We also had the benefit of a dietitian, and a health education team there that were trained as to the purpose of our degree program and in addition, were graduates of the department housing the coaching program. Opportunities to engage with interns was embraced by the medical director, and though not all practitioners worked closely with our interns, for the most part, they were able to shadow physicians, nurses, nurse practitioners, the dietitian, and others in that clinical setting. At this time, the health center on campus hopes to add a wellness coach in the near future. We found that being flexible in designing the program, making minor changes, and working with those in a non-academic setting to be key to success in the development of this program. Commonalities of the conditions seen in the field confirmed the need for coaching in unhealthy weight, obesity, metabolic issues, and hypertension which would be expected based on Mississippi's overall health status. 


\section{Limitations}

This study is limited in that we only followed interns and their experiences for three years after onset of the program. We also do not know the long-term success rates on coaching in this population. Since this was only an assessment of intern experience in selected areas of Mississippi, and its programmatic evaluation, we do not have hard data on patient clinical outcomes, which would better provide evidence of wellness coaching impacts on the patient population. Our sample of interns was also limited to the first three cohorts of students and therefore, findings only reflect those 15 participant's experiences in the program.

\section{CONCLUSION}

An internship-based wellness coaching program developed at the university graduate level can aid clinical healthcare providers in reaching patients in need of setting personal lifestyle-related goals for improving overall health outcomes. These allied health professionals can be trained to be a part of the medical team and be rated positively by medical supervisory staff. Interns must be prepared in states like Mississippi for complications such as low health literacy and low literacy situations as well as the comorbidities that a typical patient will have. Barriers to successful interaction with the wellness coach can be mitigated by having staff fully understand their role, and directly refer the patient to the coach via a personal handoff where possible. Overall, medical providers were very pleased with intern competency levels and many continued with the program over the three-year period. Additional research on individual patient health outcomes would provide needed information on the long-term effects of wellness coaching by interns in a graduate program.

\section{CONFLICT OF INTEREST STATEMENT}

The authors declare they have no conflicts of interest to report.

\section{ACKNOWLEDGMENTS}

The authors are grateful for the funding provided by the Blue Cross and Blue Shield of Mississippi Foundation (BCBSMSF2018-131B) and full support of the wellness coaching program, from conception to implementation. In addition, they wish to thank the Mississippi Agricultural and Forestry Experiment Station for research support.

\section{REFERENCES}

1. Global Wellness Institute. History of wellness. Accessed March 26, 2021. https://globalwellnessinstitute.org/industry-research/history-of-wellness/.

2. American College of Lifestyle Medicine. Accessed March 26, 2021 https://www.lifestylemedicine.org/ACLM/About/What is Lifestyle_Medicine/ACLM/About/What is Lifestyle_Medici ne_Lifestyle_Medicine.aspx?hkey=26f3eb6b-8294-4a63-83de-35d429c3bb88.

3. Wolever RQ, Simmons LA, Sforzo GA et al. A systematic review of the literature on health and wellness coaching: defining a key behavioral intervention in healthcare. Glob Adv Health Med 2013, 2:38-57. Available from: doi: 10.7453/gahmj.2013.042.

4. America's Health Rankings. United Health Foundation, Annual Report, 2020. Accessed January 20, 2021. https://www.americashealthrankings.org/.

5. America's Health Rankings. United Health Foundation, Annual Report, 2020. Mississippi Summary. Accessed March 26, 2021. https://www.americashealthrankings.org/explore/annual/measure/CHC/state/MS.

6. Trust for America's Health. The State of Obesity: Better policies for a healthier America, 2020. Accessed April 6, 2021. https://www.tfah.org/wp-content/uploads/2020/09/TFAHObesityReport_20.pdf.

7. DeJesus RS, Clark MM, Rutten LJF et al. Impact of a 12-week wellness coaching on self-care behaviors among primary care adult patients with prediabetes. Prev Med Rep 2018, 10:100-105. doi: 10.1016/j.pmedr.2018.02.012.

8. Rutten GM, Meis JJM, Hendriks MRC, Hamers FJM, Veenhof C, Kremers SPJ. The contribution of lifestyle coaching of overweight patients in primary care to more autonomous motivation for physical activity and healthy dietary behaviour: results of a longitudinal study. Int J Behav Nutr Phy Act 2014, 11:86. doi: 10.1186/s12966-0140086-z. Accessed April 1, 2021. http://www.ijbnpa.org/content/11/1/86.

9. Miller WR, Rollnick S. Motivational Interviewing. Helping people change. 3rd ed. New York: Guilford Press; 2012.

10. Lancha AH Sforzo GA, Pereira-Lancha LO. Improving nutritional habits with no diet prescription: details of a nutritional coaching process. Am J Lifestyle Med 2018, 160-165. doi: 10.1177/1559827616636616.

11. Kozica SL, Lombard CB, llic D, Ng S, Harrison CL, Teede HJ. Acceptability of delivery modes for lifestyle advice in a large scale randomized controlled obesity prevention trial. BMC Public Health 2015, 15:699. doi 10.1186/s12889-015-1995-8.

12. Xiao H, Adams SR, Goler N, et al. Wellness coaching for people with prediabetes: a randomized encouragement trail to evaluate outreach methods at Kaiser Permanente, Northern California, 2013. Prev Chronic Dis 2015, 12:150251. http://dx.doi.org/10.5888/pcd12.150251. 
13. Boccio M, Sanna RS, Adams SR et al. Telephone-based coaching: a comparison of tobacco cessation programs in an integrated health care system. Am J Health Promot 2017, 31:136-142. doi: 10.4278/ajhp.140821-QUAN-424.

14. Caldwell KL, Gray J, Wolever RQ. The process of patient empowerment in integrative health coaching: how does it happen? Global Adv Health Med 2013, 2:48-57. doi: 10.7453/gahmj.2013.026.

15. Sforzo GA, Kaye MP, Todorova I et al. Compendium of the health and wellness coaching literature. Am J Lifestyle Med 2017 doi: 10.1177/1559827617708562.

16. Roy B, Roberts $P$, Lisowski $C$, Kaye MP, Sforzo GA. Integrating health coaching with a medical fitness program to treat chronic health conditions. Am J Lifestyle Med 2020 doi: 10.1177/1559827617728025.

17. Making health communication programs work. Planner's guide. U.S. Department of Health and Human Services. The National Cancer Institute. NIH Publication No. 02-5145. September 2002. P.126-140. Bethesda, MD.

18. United States Census Bureau. Accessed April 1, 2021. https://census.gov.

19. Parents \& Kids. Reading the signs. The Mississippi literacy crisis. December 31, 2018. Accessed March $26,2021$. https://www.parentsandkids.com/18149/reading-the-signs-the-mississippi-literacy-crisis/.

20. Djuric Z, Segar M, Orizondo $\mathrm{C}$ et al. Delivery of health coaching by medical assistants in primary care. $\mathrm{J}$ am Board Fam Med 2017, 30:362-370. doi: 10.3122/jabfm.2017.03.160321.

21. Maini A, Fyfe M, Kumar S. Medical students as health coaches: adding value for patients and students. BMC Med Educ 2020 20:182 https://doi.org/10.1186/s12909-020-02096-3.

22. Venditti EM, Wylie-Rosett J, Delahanty LM, Mele L, Hoskin MA, Edelstein SL. Short and long-term lifestyle coaching approaches used to address diverse participant barriers to weight loss and physical activity adherence. Int J Behav Nutr Phy Act 2014, 11:16 doi: 10.1186/1479-5868-11-16 http://www.ijbnpa.org/content/11/1/16.

\section{APPENDIX}

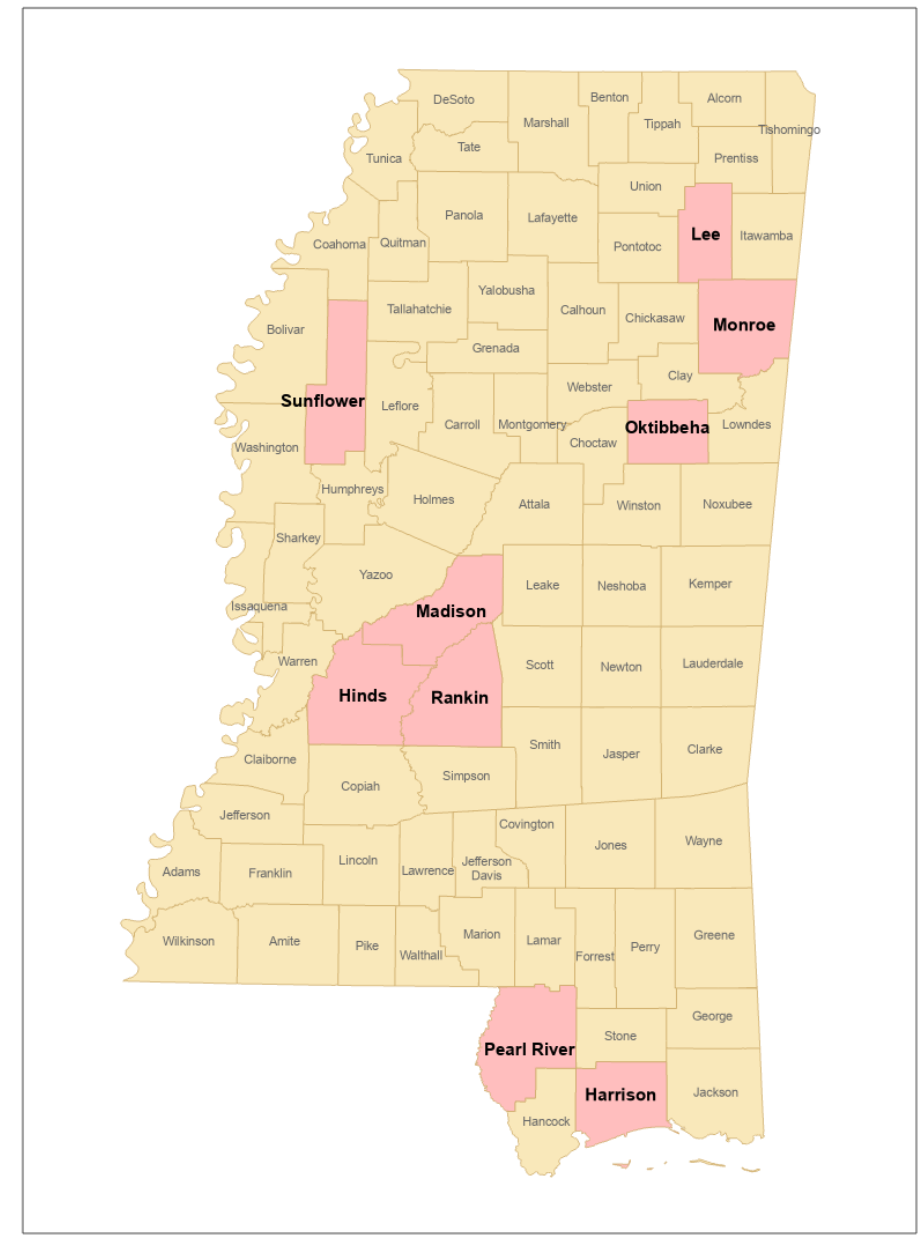

Figure 1. Map of Mississippi and Field-based Internship Locations 